\title{
Research Paper \\ Some push factors that causing Labor turnover In Private University Education in Iraq -A case study for a number of private colleges
}

Journal of

TANMIYAT ALRAFIDAIN

\section{(TANRA)}

A scientific, quarterly, international, open access, and peer-reviewed journal

Vol. 39, No. 126

June, 2020

(C) University of Mosul | College of Administration and Economics, Mosul, Iraq.

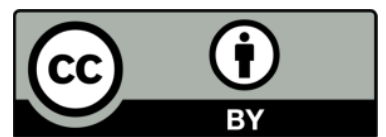

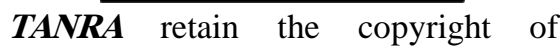
published articles, which is released under a "Creative Commons Attribution License for CC-BY-4.0" enabling the unrestricted use, distribution, and reproduction of an article in any medium, provided that the original work is properly cited.

Citation: AL Mamamry, Ahmad H. M.. (2020). "Some push factors that causing Labor turnover In Private University Education in Iraq -A case study for a number of private colleges

. TANMIYAT AL-RAFIDAIN, 39 (126), 111-131 , https://doi.org/10.33899/tanra.20 20.165654

P-ISSN: 1609-591X

e-ISSN: 2664-276X

tanmiyat.mosuljournals.com

\author{
Ahmad H. M. AL Mamamry ${ }^{1}$ \\ ${ }^{1}$ Al-Hadba Private University College
}

Corresponding author: Ahmad H. M. AL Mamamry, Department of business Administration, Al-Hadba Private University College, ahm171957@gmail.com

DOI: https://doi.org/10.33899/tanra.2020.165654

Article History: Received: / /2020; Revised. 8/3/2020; Accepted: //2020; Published: 1/6/2020.

\section{Abstract}

The faculty member is considered an essential axis in the success of the private university education.. In view of the high turnover rate in the private university education sector in Iraq, as it reached nearly $40 \%$ in some colleges, which makes it a phenomenon that must be studied by researchers. Accordingly, the research aims to find out what are the reasons that push the faculty member in private university education to lea ve his job and move to another place, which is called push factors. The researcher followed the descriptive approach in collecting theoretical information and the survey and analysis approach in collecting field data using a questionnaire that included, in addition to personal information, questions for thirteen reasons that could be cause of labor turnover send to those who left the work (Post Exit) in a sample of private colleges through Personal interview or by sending it via electronic means of communication. The data was analyzed using the statistical program SPSS version 24. The research found that the thirteen reasons were statistically significant as a reason for labor turnover, the most important of which is the lack of security and job stability in private university education. The research also presented a set of recommendations that can contribute to reducing the phenomenon of labor turnover for faculty members in private university education in Iraq.

\section{Keywords}

turnover, push factors 
ورقة بحثية

بعض العوامل الطاردة المسببة لدوران العمل في التعليم الجامعي الأهلي في العراق - دراسية تطبيقية في عدد من الكليات الأهلية أحمد حمود منصور المعماري 1 1 قسم إدارة الأعمال-كلية الحدباء الجامعة الأهلية

المؤلف المراسل: أحمد حمود منصور المعماري ، قسم إدارة الأعمال، كلية الحدباء الجامعة الأهلية ، العراق، .ahm171957@gmail.com

DOI: https://doi.org/10.33899/tanra.2020.165654

تاريخ المقالة: الاستلام: / /2020؛ التعديل والتتقيح: 2020 /2020؛ القبول: / /2020؛

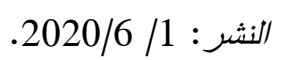

المستخلص

يتتبر عضو هيئة التدريس محورا أساسيا في إنجاح التعليم الجامعي الأهلي باعتباره العنصر الأساسي

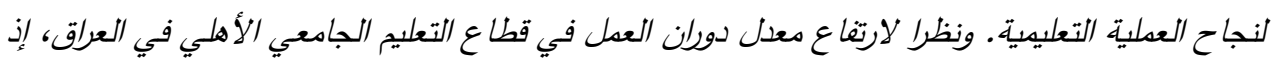

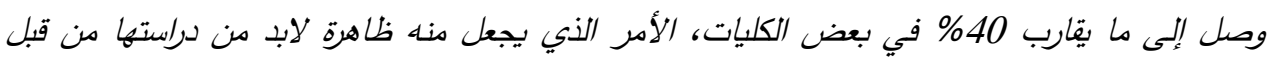

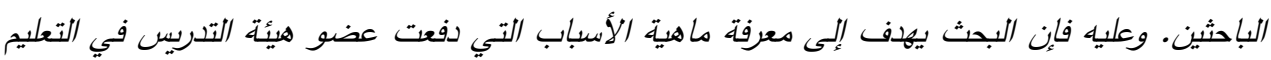

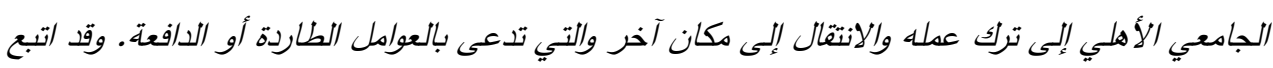

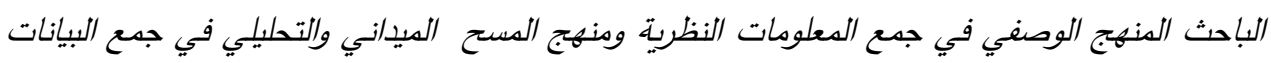

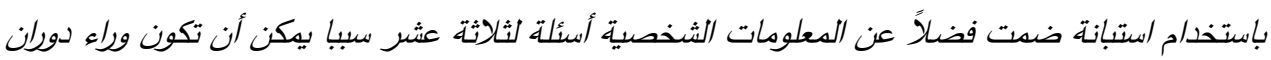

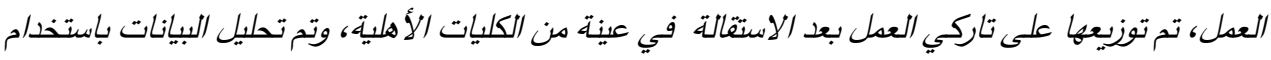

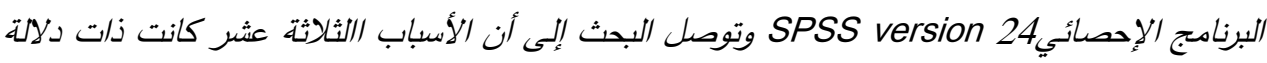

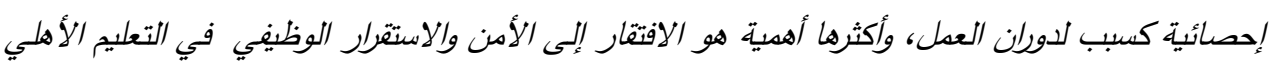

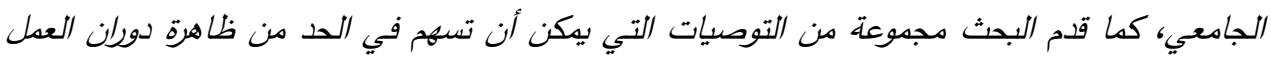

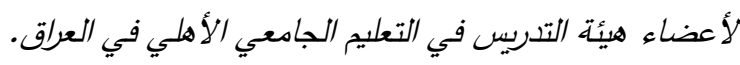

\section{الكلمات الرئيسة}

دوران العمل، العوامل الطاردة.

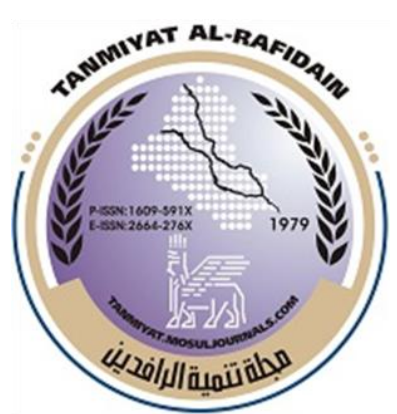

\section{هبلة}

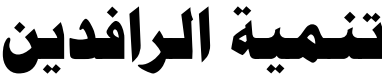

(TANRA) دولية، مفتوحة الوصول، محكمة.

$$
\text { حزيران المجلد (39)، العدد (126)، } 2020
$$

ج جامعة الموصل | كلية الإدارة والاقتصاد، الدوصل، العراق.

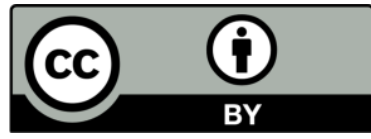

تحتظ (TANRA) بحقوق الطبع والنشر للمقالات

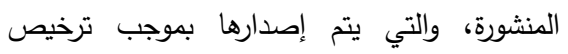
\lrcorner (Creative Commons Attribution) (CC-BY-4.0)

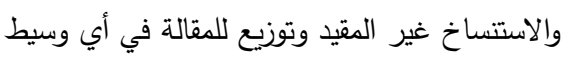
نقل، بشرط اقتباس العمل الأصلي بثكل صحيح.

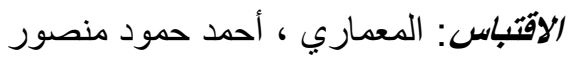

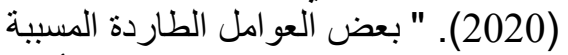
لدوران العمل في التعليم الجامعي الأهلي

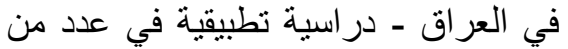
الكليات الأهلية". تنمبية الراقدين، 39 ، 131-111، (126) https://doi.org/10.33899/tanra.20 20.165654

P-ISSN: 1609-591X

e-ISSN: 2664-276X

tanmiyat.mosuljournals.com 
لقد أدى التوجه نحو الاقتصاد الحر في العراق إلى توسع هائل في قطاع التعليم العالي الذي شهد

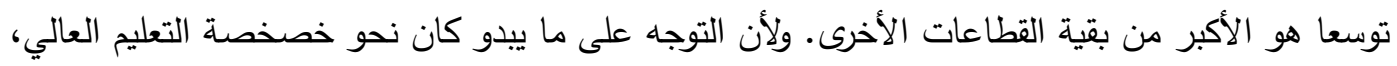

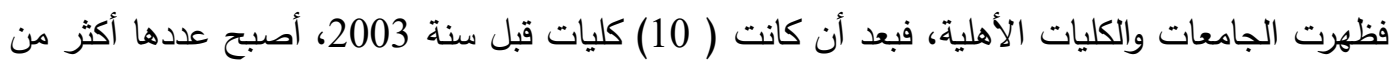
(65) جامعة وكلية في العام 2019 لتكون جزءاً هاماً من النظام الأكاديمي في العراق. إن دور الألهات الأستاذ الجامعي محوري في إنجاح العملية التعليمية، والأساس لتحسين تصنيف جودة التعليم والمؤسسة التعليمية، لكن دوران العمل قد يقوض هذه الجودة (Ramasamg \& Bint:169; Abdullah,2017) • وعلى الرغم

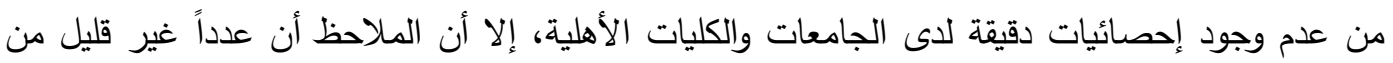

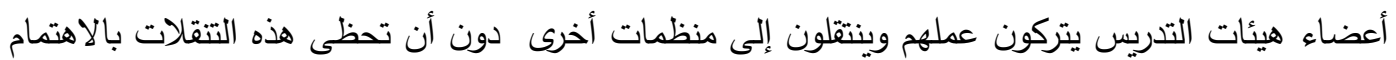

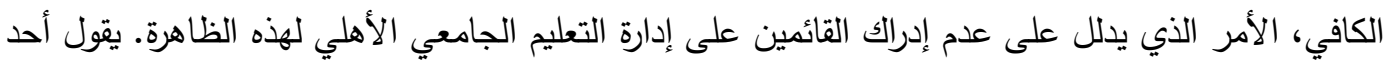

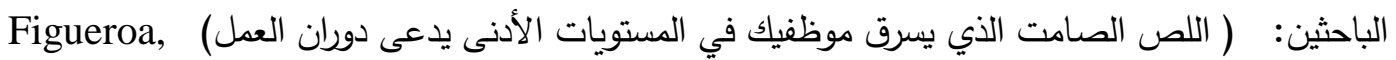

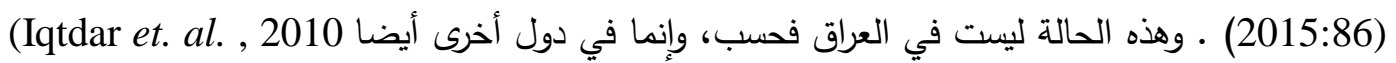
(169:. من هنا أصبحت مسألة دوران العمل لاعضاء هيئة التدريس لا يمكن تجاهلها في مؤسسات التعليم الجامعي الأهلي في العراق. للدور العام الذي يؤديه المدرسون في التعليم باعتبارهم أهم عوامل نجاح العملية التعليمية (2: Tohompsom, 2018 )

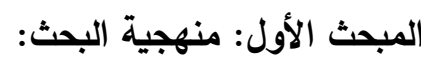

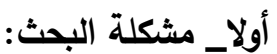
لا يخلو التعليم الجامعي الأهلي في كثير من دول العالم من عدم استقرار أعضاء هيئة التدريس

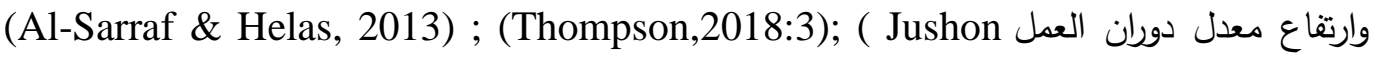
\&Yue, 2019: 123).

في العراق وعلى الرغم من عدم وجود إحصائيات عن معدل دوران العمل في التعليم الجامعي

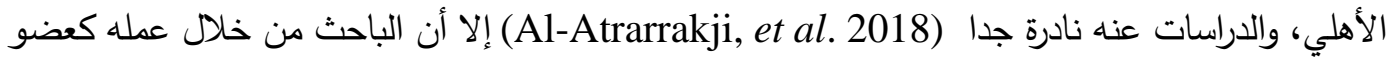

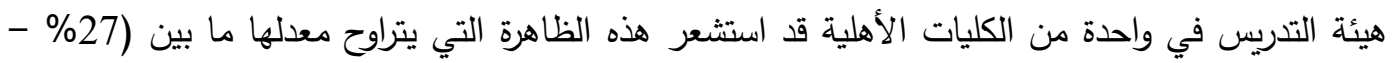
39\% في الكليات عينة البحث للعام الدراسي 2018-2019 وهناك هملة من العوامل الطاردة تكمن وراء ذلك، بالرغم اختلاف تأثيرها من فرد إلى آخر • وعليه فإن مشكلة البحث تتمثل بإثارة السؤالين الآتيين؟

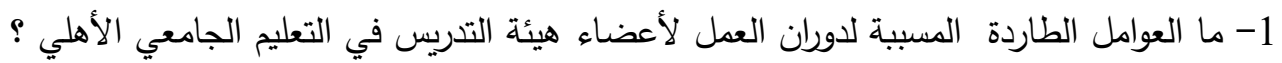

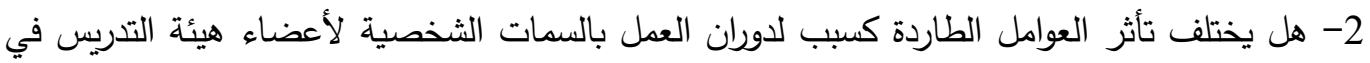

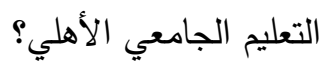




$$
\text { ثانيا-هدف البحث: }
$$

1- يهدف البحث إلى تشخيص الأسباب التي كانت وراء دوران العمل لأعضاء هيئة التدريس في التعليم

$$
\text { الجامعي الأهلي في العراق. }
$$

2- تقليل الفجوة البحثية في موضوع دوران أعضاء هيئة التدريس في التعليم الجامعي الأهلي في العراق

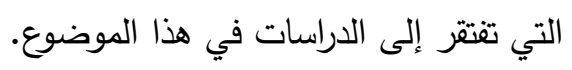

3- لعل نتائج البحث تساعد القائمين على إدارة الجامعات والكليات في التعليم الجامعي الأهلي على معرفة

وفهم الأسباب التي تكمن وراء هذه الظاهرة من أجل وضع الحلول حول كيفية تقليل معدل دوران العمل، وتحسين مستوى الإبقاء على أعضاء هيئة التدريس لأطول فترة مدكنة.

$$
\text { ثالثاً - أهمية البحث: تكمن آهمية البحث في الآتي: }
$$

1- تشخيص العوامل الطاردة للكفاءات العلمية في التعليم الجامعي الأهلي بأسلوب لم يكن مطروحا من قبل العبل إلا نادراً.

2- الدراسة قد تقيد القائمين على إدارة الجامعات والكليات الأهلية للاطلاع على أسباب ترك أهم مواردهم البشرية للعمل معهم واتخاذ الإجراءات اللازمة للحد من هذه الظاهرة.

3- إن هذه الدراسة قد تكون من الدراسات النادرة من نوعها في العراق من حيت استطلاع آراء أعضاء أعضاء هيئة

التدريس في التعليم الجامعي الأهلي بعد مغادرتهم الكليات التي عملوا فيها عن أسباب تركهم العمل.

$$
\text { رابعا: مخطط البحث: }
$$

يتمثل المخطط الافتراضي للبحث في الثكل رقم (1) الذي يوضح بعض العوامل الطاردة والمسببة

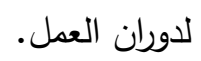




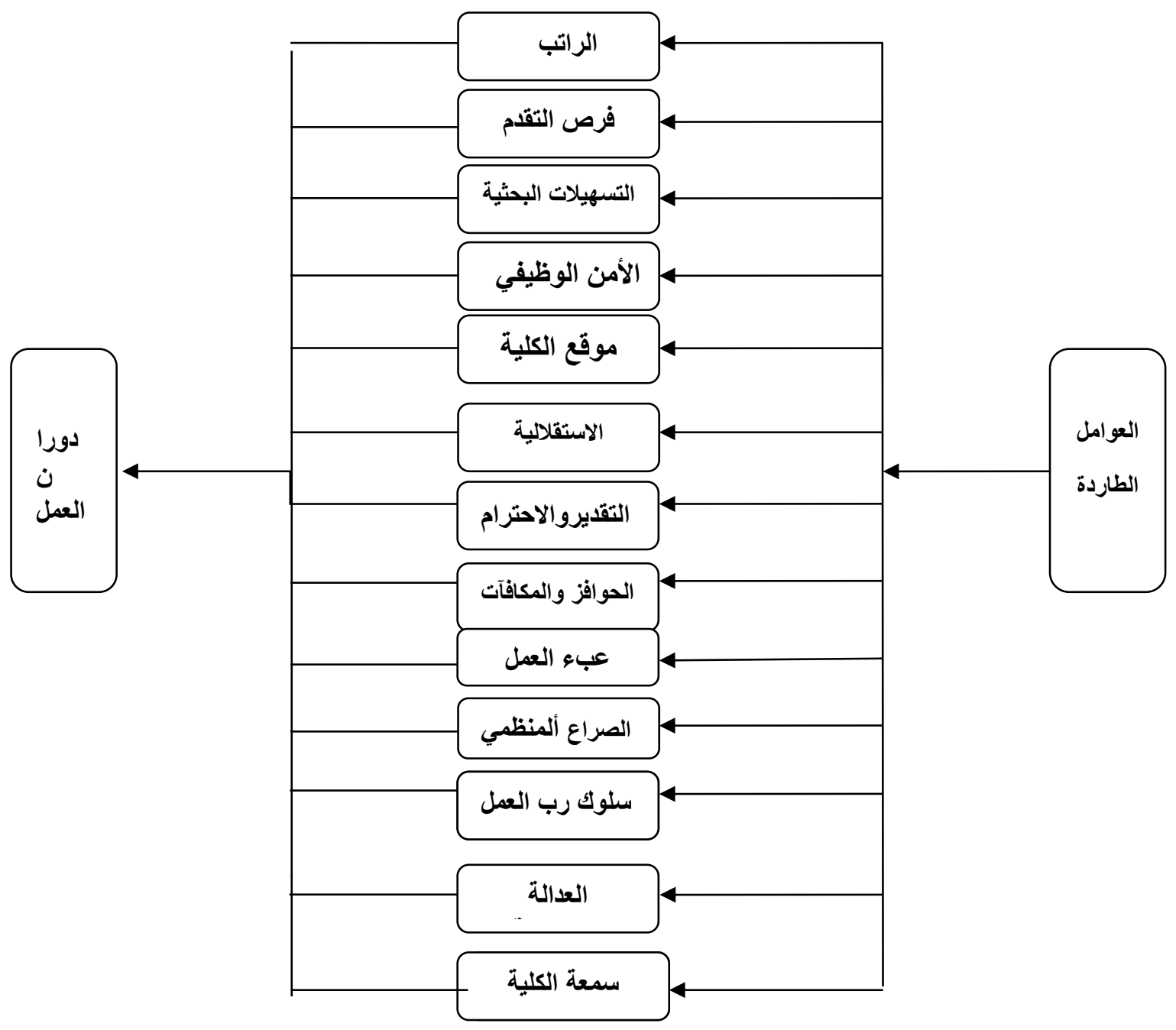

شكل رقم (1): مخطط البحث الفرضي

$$
\text { رابعاً- فرضيات البحث: }
$$

الفرضية الرئيسة رقم (1): أسهمت جملة من العوامل الطاردة في دوران العمل لأعضاء هيئة التدريس في

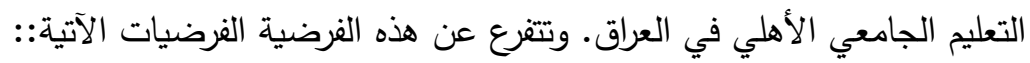

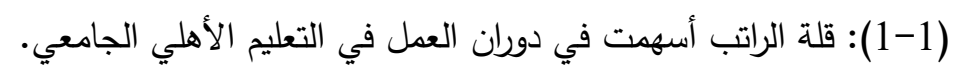

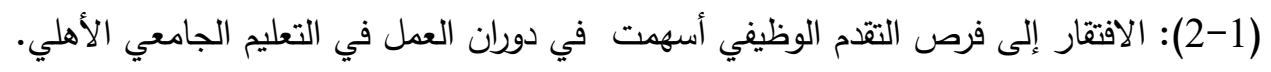

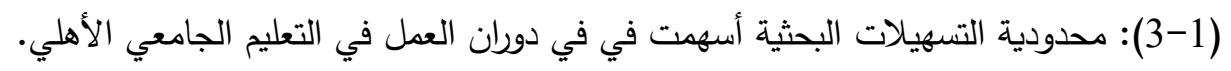

(1-4) : انعدام الأمن الوظيفي أسهم في دوران العمل في التعليم الجامعي الأهلي. 
(1-5): موقع الكلية غير المناسب أسهم في دوران العمل في التعليم الجامعي الأهلي.

(1-6): ضعف الاستقلالية في العمل أسهمت في دوران العمل في التعليم الجامعي الأهلي. (1-7): قلة التقدير والاحترام في بيئة العمل أسهمت في دوران فئن فئ دوان العمل في التعليم الجامعي الأهلي.

(1-8): ضعف نظام الحوافز والمكافآت أسهح في دوران العمل في التعليم الجامعي الأهلي.

(1-9): زيادة عبء العمل عن المقرر أسهمت في دوران العمل في التعليم الجامعي الأهلي.

(10-10): وجود الصراع في بيئة العمل أسهم في دوران العمل في التعليم الجامعي الأهلي.

(1-11): السلوك غير المناسب من رب العمل أسهم في دوران العمل في التعليم الجامعي الأهلي.

(12-12): الافتقار إلى العدالة التنظيمية أسهمت في دوران العمل في التعليم الجامعي الأهلي.

(13-13): سمعة الكلية غير الجيدة أسهمت في دوران العمل في التعليم الجامعي الأهلي.

الفرضية الرئيسة رقم (2): لا توجد فروق ذات دلالة إحصائية عند مستوى دلالة (0.05) للعوامل الطاردة

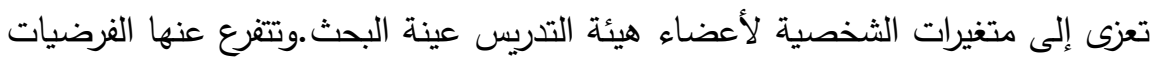

$$
\text { الآتية: }
$$

(2-1): لا توجد فروق ذات دلالة إحصائية عند مستوى دلالة (0.05) للعوامل الطاردة كسبب لدوران العمل

وفقا لمتغير الجنس.

(2-1): لا توجد فروق ذات دلالة إحصائية عند مستوى دلالة (0.05) للعوامل الطاردة كسبب لدوران العمل

$$
\text { وفقا لمتغير الحالة الزوجية. }
$$

(2-3): لا توجد فروق ذات دلالة إحصائية عند مستوى دلالة (0.05) للعوامل الطاردة كسبب لدوران العمل

$$
\text { وفقا لمتغير التحصيل الدراسي. }
$$

(4-4): لا توجد فروق ذات دلالة إحصائية عند مستوى دلالة (0.05) للعوامل الطاردة كسبب لدوران العمل

$$
\text { وفقا لمتغير اللقب العلمي. }
$$

(2-5): لا توجد فروق ذات دلالة احصائية عند مستوى دلالة (0.05) للعوامل الطاردة كسبب لدوران العمل

$$
\text { خامساً: حدود البحث }
$$

المكانية: اختيار أربع من والكليات الأهلية لتكون موقع البحث وهي (المعارف، والحدباء، والقلم، والنور)

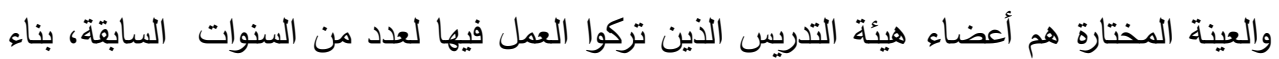
على طلبهم (الاستقالة) والذين تمكن الباحث من إيصال استبانة البحث إليهم.

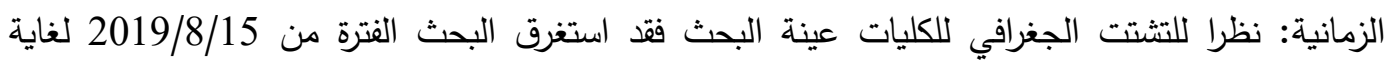
$.2020 / 2 / 1$ 
سادساً: الصعوبات التي واجهت الباحث أ- صعوبة الحصول على عدد تاركي العمل وعناوينهم من أعضاء هيئة التدريس في الكليات المبحوثة لعدم

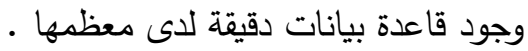
ب- لم يتمكن الباحث من الوصول إلى عدد من تاركي العمل أو عناوين عملهم أو عناوينهم الإكترونية للتواصل معهم ولإيصال استبانة البحث إليهم. د- لم يقم بعض من المشمولين بالبحث بإعادة استبانة البحث. سابعاً: أساليب جمع البيانات اعتمد الباحث أسلوب الاستبيان وتوزيعه على عينة البحث بعد تركهم العمل (الاستقالة) من الكليات الأهلية بفترة زمنية باسلوب يطلق عليه ما بعد المغادرة (Spot Exit) الأمر الذي يمنح المستجيبين حرية أكبر في التعبير عن آرائهم. وقد تم تصميم استبانة البحث بعد الاطلاع على عدد من الدراسات التي تتاولت دراسة موضوع (Iqutidar et al., 2010; Mohmmad, 2016; Sohhel دوران العمل بأسلوب العوامل الطاردة Chowdhary, 2016; ) ، وترجمتها إلى اللغة العربية - وعلى ضوء خبرة الباحث كونه يعمل في التعليم

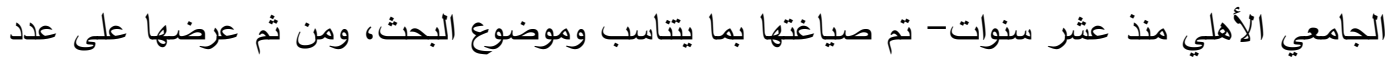
من الخبراء المحكمين"، وتم الأخذ بملاحظاتهم، ومن ثم توزيع عشرة استبيانات على عينة من المبحوثين

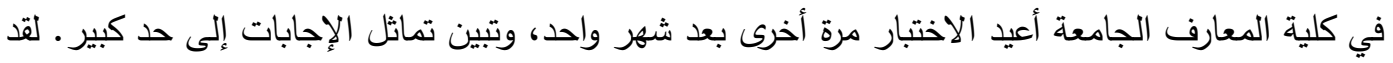

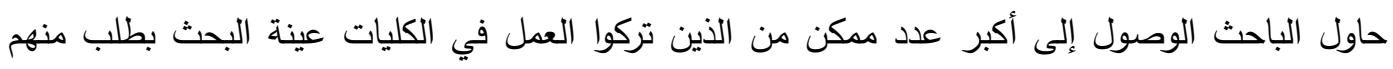

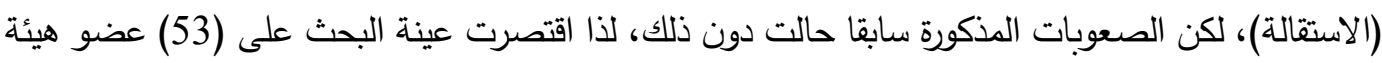
تدريس من مجموع (70) استبانة تم توزيعها.ولغرض التعرف على مدى صلاحية المقياس وثبات الاستبانة تم ايجاد مقياس Cronbach Alpha) لتحديد درجة تباين أداة القياس في هذه الدراسة، وقد بلغ (905.)

$$
\text { وهو على درجة عالية جدا من المقبولية.1 }
$$

$$
\text { أولاً: تعريف دوران العمل: الإطار النظري }
$$

يعرف دوران العمل على أنه حركة الأفراد عبر حدود المنظمة (Andrea, 2010:7) وهو يثير إلى كلا الحركتين الداخلة والخارجة. وعرفه (111 : Mobely,1982) أنه عدد الأفراد الذين يتركون العمل

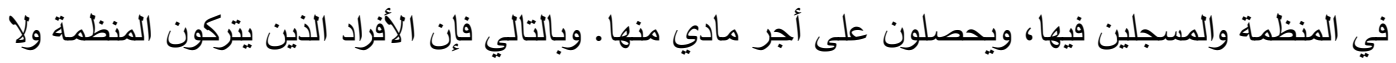


يتقاضون أجراً هم غير داخلين في دوران العمل. وتصنف حركة الأفراد الخارجين من المنظمة إلى نوعين

(Choon, et al., 2013:47)

1- دوران العمل الطوعي (Voluntary turnover)وهو ترك الفرد العمل في المنظمة بإرادته، وهو ما

يعرف بالاستقالة.

2- دوران العمل الإجباري(Involuntary turnover) وهو إجبار المنظمة للفرد على ترك العمل فيها،

مثل تسريح الفرد بسبب ضعف الأداء أو الاستغناء عنهم وطردهم لفترات قصيرة بسبب الظروف الاقتصادية وتقليص نشاط المنظمة أو بسبب انتهاء مدة العقود المبرمة معهم. والنوع الأول أصبح الأساس في دراسات الدوران في المنظمات.

ثانيا: أهمية دراسة دوران العمل:

تكاد أن تكون ظاهرة دوران العمل لا تخلو منها أي من مؤسسات التعليم العالي الخاص في كثير

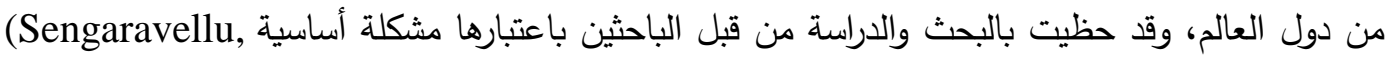
2018);( Ramasamy \& Bint Abdullah,2017); Hammond \& kutsanedzie,2015);

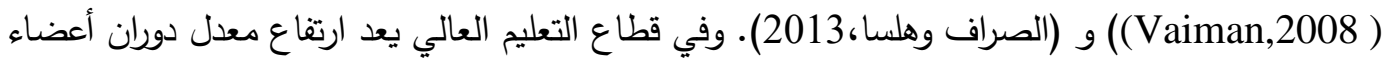
هيئة التدريس مسألة في غاية الأهمية، لأنه العنصر الأساسي للمنافسة في هذا القطاع، فهو قد يقوض الكفاءة والإنتاجية وفي بعض الحالات يهدد بقاء المؤسسة التعليمة على المدى الطويل Ramasamy \& Bint) Abdullah, 2017:169); ((Hammond \& kutsanedzie, 2015: 6) ; (Thompson,2018:2) ومع أن كثيراً من مؤسسات التعليم الجامعي الأهلي لا تدرك التكاليف الحقيقية للدوران وما يترتب على ذلك : الك من تكاليف تتحملها المؤسسة التعليمية (Vaiman, 2008:173); ) (Nair,el al.,2016:110) (V) فهو ينطوي على تكاليف عالية حيث (Tracey\& Henkin, 2010);(Holtom et al., 2008: 236) الموارد البشرية ذات المعرفة والكفاءة هي الاصول الرئيسة، وتؤثر على الأنشطة الأكاديمية والبحثية للمؤسسة التعليمية (Iqtdar et al,2010:168)، فقد قدرت هذه التكاليف الدوران في مؤسسات التعليم العالي في الولايات المتحدة الأمريكية عام 2008 بحدود (68) مليون دولار، لكن الكلفة الفعلية قد تكون أعلى بكثير ) (Vaiman, 2008: بصورة عامة تقسم تكاليف دوران العمل على نوعين Figureo, 2015: 86)

17);(Traccey \& Hinkin, 2010: 13)

1- التكاليف المباشرة: ويسميها البعض بالتكاليف الصلبة (Hard costs) وتتمثل في تكاليف التوظيف والإحلال وتدريب الموظفين الجدد، وهي تكلفة كبيرة لو كانت إدارات المنظمات تدركها. فعلى سبيل المثال بلغت تكلفة إعداد تدريسي واحد للحصول على شهادة الدكتوراه وعلى نفقة إحدى كليات عينة

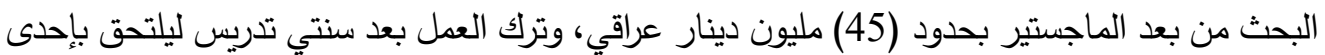
الجامعات الحكومية. 2- التكاليف غير المباشرة: وتدعى أيضا بالتكلفة الناعمة أو اللينة ( Soft costs) وهي تكاليف يصعب تقديرها ومنها: 
أ- فقدان المعرفة الضمنية (tacit knowledge) التي يمتلكها عضو هيئة التدريس المتمثلة في المعارف والخبرات والقدرات المهنية والعلاقات مع الأطراف ذات المصلحة مع المنظمة، وهي فريدة من نوعها، ويصعب تقديرها وتعويضها ولها القدرة على تكوين القيمة الاستراتيجية والميزة التتافسية للمؤسسة التعليمية (Vaiman, 2008: 173.) ب- انخفاض الروح المعنوية للباقين لما يتحملونه من عبء عمل إضافي إذا ما فثلت المنظمة من (Manogharan, et al., 2018: 52); (Wang et al., 2017: 21); تعيين جدد

(Manogharan, 2018: 52) ج- وتأثيره على الأداء الأكاديمي للطلاب وإرباك سير العملية التعليمية خاصة إذا كان الترك في منتصف الفصل الدراسي (Thompson, 2018:2). د- انخفاض إنتاجية القادمين الجدد وربما الباقين أيضا، وهذا قد يؤثر على جودة نتائج العملية التعليمية والبحث والتطوير (4enggaravellu, 2018). وبالتالي على تصنيف المؤسسة التعليمية.

وعلى الرغم من صعوبة تقدير التكاليف الناعمة لكن يرى بعض الباحثين المتخصصين أن مثل هذه

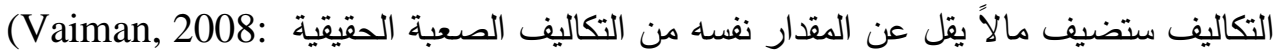

ثالثا: العوامل المؤثرة على دوران العمل:

يتقق الباحثون على وجود عوامل متعددة تؤدي إلى دوران العمل الطوعي (Along,2014:2) ويصعب القول إن أحداً من الباحثين قد أحاط بها في دراسة واحدة. فهي تختلف بحسب بيئة الدراسة ورؤية

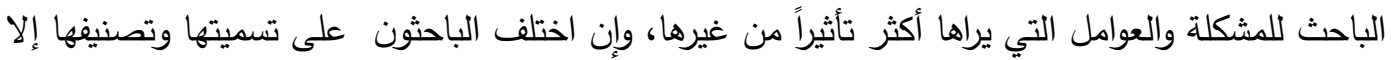
أن الأغلبية تتفق على مجموعتين رئيستين هما:

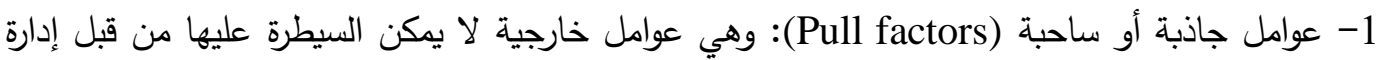

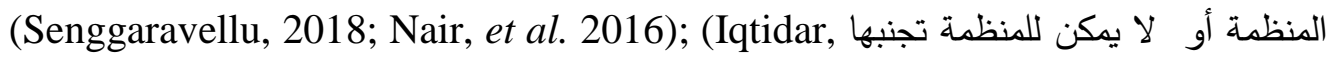
.et al. 2010) 2- عوامل طاردة أو دافعة (Push Factor): وهي العوامل التي تدفع الفرد إلى ترك عمله والانتقال إلى (Ch) منظمة أخرى(Chowdhury, 2016: 2) وتدعى أيضا بالعوامل الداخلية أو العوامل التي يمكن تجنبها باعتبار أن الإدارة القائمة على المنظمات قادرة على تجنيها والسيطرة عليها. ولما كانت العوامل الطاردة العوامل هي عوامل داخلية يمكن السيطرة عليها من قبل إدارة المنظمات، فقد حظيت بالدراسة والبحث من

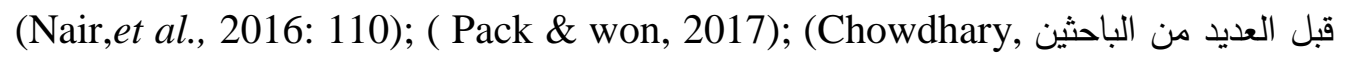
$.2016: 3)$ 
ونظراً لتتوع العوامل الطاردة في المنظمات فقد يصعب حصرها في دراسة واحدة. فقد شملت دراسة

(Iqtidar,2010) الأمن الوظيفي، صغر حجم المنظمة، الموقع، بيئة العمل، نقص الحوافز، الصراع بين العاملين، قلة التقدير للجهود المبذولة، نقص الاستقلالية في العمل، الافتقار إلى دعايير التقدم الوظيفي، نقص التسهيلات البحثية، زيادة العبء المكتبي، زيادة العبء التعليمي، ممارسات الإدارة، تمكين العاملين، عدم توافر وقت كافٍ للعائلة).

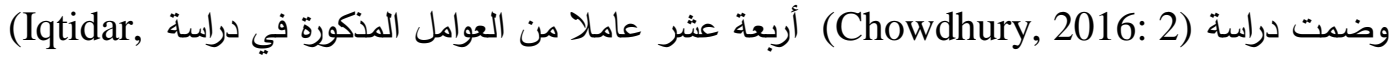

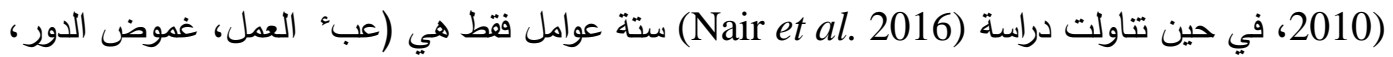
الصراع، الأجور ، سمعة المنظمة، وموقع العمل). وفي هذا البحث تم تتاول العوامل الطاردة push factors باعتبارها عوامل داخلية يمكن السيطرة عليها من قبل القائمين على إدارات التعليم الجامعي الأهلي، وتم اقتراح ثلاثة عشر عاملاًا يمكن أن تكون

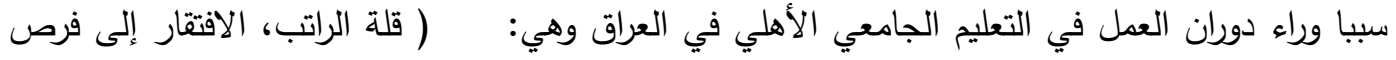
التقدم والترقية، محدودية التسهيلات البحثية، انعدام الأمن والاستقرار الوظيفي، موقع العمل غير المناسب،

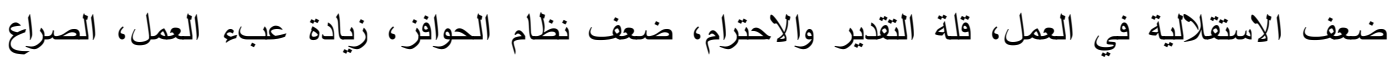
التتظيمي في بيئة العمل، سلوك رب العمل غير الملائم، الافتقار إلى العدالة التتظيمية، وسمعة الكلية).

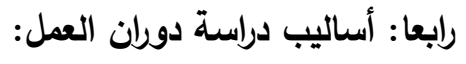

تتم دراسة دوران العمل وفقا للطرائق الآتية: أ- النية في ترك العمل (Intention to live ) وهي من أكثر الطرائق المتبعة من قبل الباحثين في دراسة العوامل المؤثرة على دوران العمل الطوعي نظرا لأن هذا الأسلوب يعد أكثر سهولة وميسرا أمام الباحثين،

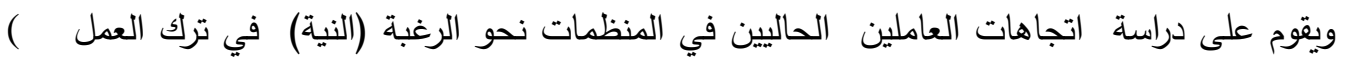
لكن هذا الأسلوب لا يقدم تقسيراً (Martin, 1979;Henry,2007; Rothkorishon et al,2016)

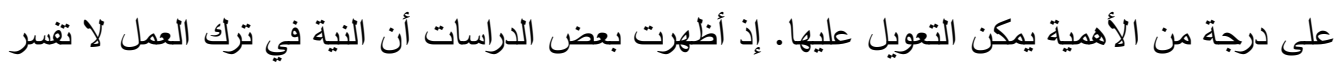
أكثر من (15\%) من التباين في دوران العمل، وأن غالبية الموظفين الذين يبلغون عن نيتهم في ترك الده

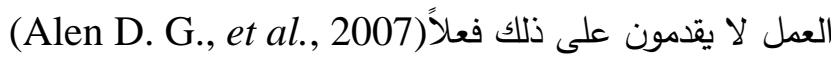
ب- مقابلة تاركي العمل : وفيها طريقتان هما : 1- المقابلة قبل المغادرة (Exit interview): وتتم خلال اجراءات تقديم طلب الاستقالة وقبل الانفكالك من المنظمة، وهي أفضل من الطريقة السابقة، ويمكن الحصول من خلالها على الأسباب الحقيقية

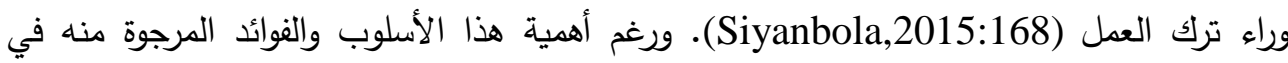
الوصول إلى الأسباب الأكثر صلة بالدوران إلا أن هذا الأسلوب يعد قليل الاستخدام من قبل الباحثين 
حتى في الدول المتقدمة، وقد يكون نادراً في بلدان العالم الثالث (Sigunbolo, 2015: 168) لعدة

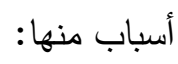

- يتطلب تطبيق هذا الأسلوب وجود إدارة موارد بشرية فعالة، وتقدر أهمية العنصر البشري العامل

لايها، وتقوم بإجراء مقابلة للعاملين قبل انفكاكهم من المنظمة. - إتباع هذا الأسلوب يستغرق وقتا أطول وتكاليف أكثر من قبل القائمين عليه.

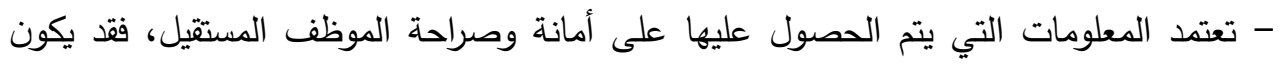

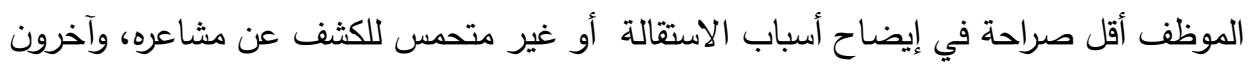

قد لا يريدون قول شيء سيء عن المنظمة خاصة لمن يفكر العودة إليها مرة أخرى.

2- المقابلة بعد المغادرة (Spot interview): وبموجب هذا الأسلوب يتم مقابلة تاركي العمل فئل

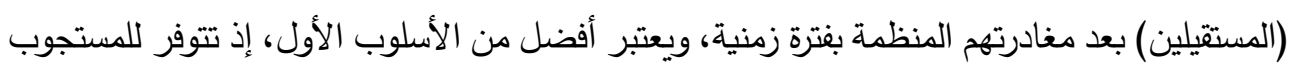

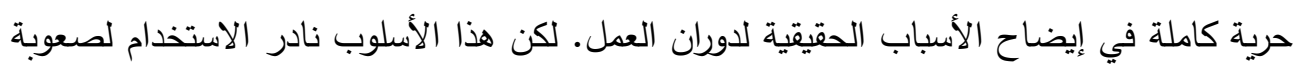

الوصول إلى الأفراد المستثيلين بعد تركهم العمل (Siganbola, 2015:167).

$$
\begin{aligned}
& \text { المبحث الثالث: الجانب الميداني } \\
& \text { أولاً - مجتمع البحث }
\end{aligned}
$$

يضم مجتمع البحث أربعاً من الكليات الأهلية المبينة في الجدول (1) ومؤشرا ازاء كل منها معدل

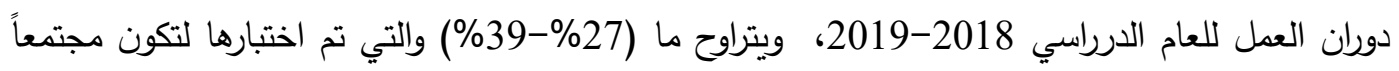
للبحث لأن الباحث عمل في اثثين منها ( كليتي المعارف والحدباء)، وسهولة التواصل مع الأخريين ( كليتي

\begin{tabular}{|c|c|c|c|}
\hline الاستبانات المعادة & الاستبانات الموزعة & معدل دوران العمل\%\% & الكلية \\
\hline 16 & 23 & 35 & المعارف \\
\hline 19 & 23 & 39 & الحدباء \\
\hline 13 & 18 & 29 & القلم \\
\hline 5 & 6 & 27 & النور \\
\hline 53 & 70 & 32.5\% المعدل العام & المجموع \\
\hline
\end{tabular}

النور والقلم). وقد تم توزيع (70) استبانة واستعادة (53) منها فقط، وكما مبين في الجدول (1).

جدول (1): معدل دوران العمل في الكليات عينة البحث والاستبانات الموزعة والمعادة 
ثانيا: وصف عينة البحث

يبين الجدول (2) التوزيع الديموغرافي لعينة الباحث البالغة (53) من أعضاء هيئة التدريس الذين

تركوا العمل في الكليات الأهلية عينة البحث. ومنه يتضح الآتي:

1- إن أغلب تاركي العمل هم من أعضاء هيئة التدريس الذكور بعدد(44) ونسبة (83\%)، في حين بلغ عدد الاناث تاركات العمل (9) فقط وبنسبة (17\%) وقد يعزى ذلك إلى أن عدد الرجال في التعليم الجامعي الأهلي هم بالأساس أكثر من النساء، فضلا عن أن الرجال أكثر ميلا من النساء للانتقال من جامعة إلى إنى

2- معظم عينة البحث هم من المتزوجين بعدد (47) وبنسبة (89\%) في حين بلغ عدد العزاب (6) فقط وبنسبة (11\%) وهذا قد يعود إلى أن معظم أعضاء هيئة التدريس هم في سن الزواج كما سيتضح في متغير العمر. 3- التحصيل الدراسي: بلغ عدد حملة شهادة الماجستير (30) وبنسبة (56.6\%) وهي أكثر من نصف العينة، في حين بلغ عدد حملة شهادة الدكتوراه (23) وبنسبة (43\%) ويمكن أن يعزى ذلك إلى أن حملة شهادة الماجستير يشكلون أغلبية أعضاء هيئات التدريس في التعليم الجامعي الأهلي أان دوران العمل بين حملة شهادة الماجستير أكثر منه من حملة شهادة الدكتوراه في التعليم الجامعي الأهلي. 4- إن (22) من أعضاء هيئة التدريس تاركي العمل يحملون لقب مدرس مساعد وبنسبة (41.5\%) وفي حين من يحمل لقب مدرس بلغ (21) وبنسبة (39.6\%)، ومن يحمل لقب استاذ مساعد (7) فقط وبنسبة (13.2\%)، ولقب استاذ (1) فقط وبنسبة (1.9) وهذا مؤشر على أن دوران العمل بين حملة الألقاب العلمية الأدنى هو الأكثر، وهذا ربما يتعلق بالفقرة السابقة،إذ كان الدوران بين حملة الماجستير هو

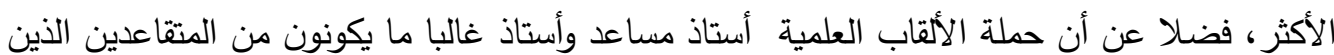

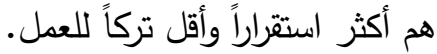

جدول (2): توزيع عينة البحث بحسب المتغيرات الديموغرافية

\begin{tabular}{|c|c|c|c|}
\hline \multicolumn{2}{|c|}{ 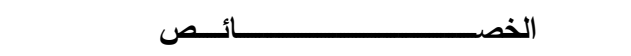 } & & المتغير \\
\hline إناث & ذكور & & \\
\hline 9 & 44 & العدد & الجنس \\
\hline 17 & 83 & النسبة\% & \\
\hline 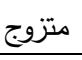 & 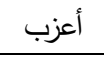 & & \\
\hline 47 & 6 & العدد & الحالة \\
\hline 89 & 11 & النسبة\% & الاجتماعية \\
\hline دكتوراه & ماجستير & & التحصيل \\
\hline 23 & 30 & العدد & الدراسي \\
\hline
\end{tabular}




\section{بعض العوامل الطاردة المسببة لدوران العمل في التعليم........}

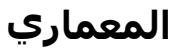

\begin{tabular}{|c|c|c|c|c|c|c|}
\hline \multicolumn{2}{|c|}{43.4} & \multicolumn{3}{|c|}{56.6} & النسبة\% & \\
\hline استاذ & استاذ مساعد & \multicolumn{2}{|c|}{ مدرس } & مدرس مساعد & & \multirow{3}{*}{ اللقب العلمي } \\
\hline 3 & 7 & \multicolumn{2}{|c|}{21} & 22 & العدد & \\
\hline 5.7 & 13.2 & \multicolumn{2}{|c|}{39.6} & 41.5 & النسبة\%\% & \\
\hline أكثرمن10 & من 7-9سنة & \multicolumn{2}{|c|}{ من 4-6سنة } & إلى 3 سنوات & & \multirow{3}{*}{ قدة الخدمة } \\
\hline 11 & 7 & \multicolumn{2}{|c|}{10} & 25 & العدد & \\
\hline 21 & 13 & \multicolumn{2}{|c|}{19} & 47 & النسبة\% & \\
\hline أكثر من 60 سنة & من 51-60 سنة & من 41-50 & من31-40 & اقل من30سنة & & العمر \\
\hline 7 & 15 & 7 & 21 & 3 & العدد & \\
\hline 13.2 & 28.3 & 13.2 & 39.6 & 5.7 & النسبة\%\% & \\
\hline
\end{tabular}

SPSS. المصدر: الجدول من إعداد الباحث بناء على نتائج التحليل الإحصائي لبرنامج

5- اما من حيث العمر فيتضح أن أغلب تاركي العمل هم دون الأربعين سنة، إذ بلغ عددهم (24) وبنسبة (46.3\%)، ومن فئة (41-50 سنة) بلغ (7) فقط بنسبة (13.2\%)، ومن فئة (51-60 سنة) بلغ (15) وبنسبة (28.3\%)، وأكثر من 60 سنة بلغ (7) وبنسبة (13.3\%). وهذا مؤشر على أن دوران العمل في

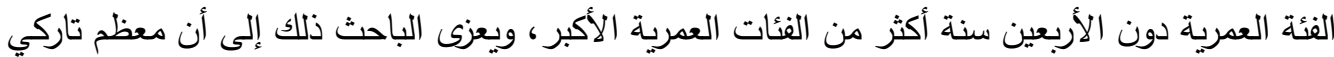
العمل هم ضمن السن القانونية التي تسمح لهم بالحصول على فرصة عمل لاى القطاع الحكومي، وأنهم

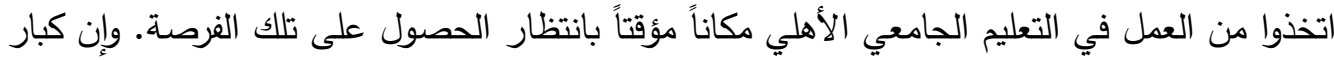
السن هم أكثر استقرارا في الكليات ولا سيما أن الكثير منهم من أساتذة الجامعات الحكومية المتقاعدين، وهذا يتفق ودراسة (Choong, et al.,2013:46).

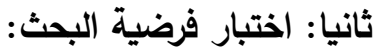

الفرضية رقم (1): أسهمت العوامل الطاردة في دوران العمل لأعضاء هيئة التدريس في التعليم

$$
\text { الجامعي الأهلي في العراق. }
$$

يبين الجدول (3) العوامل الأربعة عشر الطاردة مؤشر إزائها الوسط الحسابي والانحراف المعياري ومؤشر الدلالة الإحصائية Sig وقيمة T المحسوبة وفقا لما تم الحصول عليه من تحليل البيانات التي تم الحصول عليها بالبرنامج الإحصائي (SPSS. Version 24). ومن الجدول يبدو أن كل العوامل الطاردة متوسطها الحسابي أكثر من الرقم (3) الذي هو المتوسط الحسابي للمقياس، وبانحرافات معيارية متفاوتة وأن جميعاً بدلالة إحصائية عند مستوى معنوية (05.) و (01.) حيث قيمة (sig=.000) لكل المتغيرات، الأمر الذي يعني أن جميع المتغيرات موضوع الدراسة كانت عاملاً طارداً متسبباً في دوران العمل لأعضاء هيئة إلهاء 
التدريس عينة البحث، فضلاً عن المتوسط العام لها فقد بلغ (3.4147) وبانحراف معياري (86049.) وبدلالة إحصائية حيث (Sig=000).وهي بحسب الترتيب من حيث قيمة الوسط الحسابي وكما يأتي:

جلول (3): المتوسط الحسابي واختبار T Test

\begin{tabular}{|c|c|c|c|c|c|c|}
\hline الترتيب & $\mathbf{T}$ & Sig & $\begin{array}{c}\text { Std. } \\
\text { Deviation }\end{array}$ & Mean & المتغير & 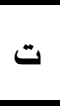 \\
\hline i-5 & 18.206 & .000 & 1.38072 & 3.4528 & قلة الراتب & 1 \\
\hline 3 & 22.195 & .000 & 1.19445 & 3.6415 & الافتقار إلى فرص التقدم الوظيفي & 2 \\
\hline 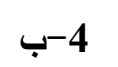 & 27.302 & .000 & .95090 & 3.5660 & محدودية التسهيلات البحثية & 3 \\
\hline 1 & 24.193 & .000 & 1.19232 & 3.9623 & الافتقار إلى الامن والاستقرار الوظيفي & 4 \\
\hline 7 & 17.595 & .000 & 1.40520 & 3.3962 & موقع الكلية غير المناسب & 5 \\
\hline 2 & 24.249 & .000 & 1.11592 & 3.7170 & ضعف الاستقلالية في العمل & 6 \\
\hline 8 & 17.066 & .000 & 1.40856 & 3.3019 & قلة الاحترام والتقدير في بيئة العمل & 7 \\
\hline 6 & 20.028 & .000 & 1.24822 & 3.4340 & ضعف الحوافز والمكافآت & 8 \\
\hline 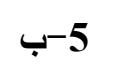 & 20.377 & .000 & 1.23360 & 3.4528 & زيادة عبء العمل عن المقرر & 9 \\
\hline 9 & 17.836 & .000 & 1.33230 & 3.2642 & وجود صراع في بيئة العمل & 10 \\
\hline أ-10 & 16.520 & .000 & 1.39692 & 3.1698 & السلوك غير المناسب من رب العمل & 11 \\
\hline أ-4 & 19.205 & .000 & 1.35177 & 3.5660 & الافتقار إلى العدالة التنظيمية & 12 \\
\hline \multirow[t]{2}{*}{ 10 } & 17.212 & .000 & 1.34072 & 3.1698 & سمعة الكلية غير الجيدة & 13 \\
\hline & 28.889 & .000 & .86049 & 3.4146 & المتوسط العام & 14 \\
\hline
\end{tabular}

المصدر: الجدول من إعداد الباحث بالاعتماد على نتائج التحليل الإحصائي Spss

1- الافتقار إلى الأمن والاستقرار الوظيفي: حيث بلغ المتوسط الحسابي (3.9623) بانحراف معياري (1.19232) و بدلالة معنوية (sig=.000) الأمر الذي يعني أن فقدان الأمن الوظيفي كان أحد أهم

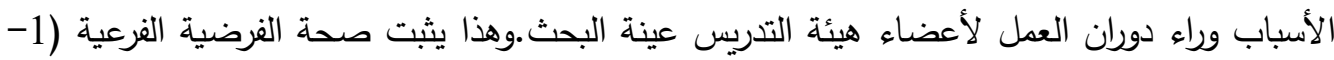

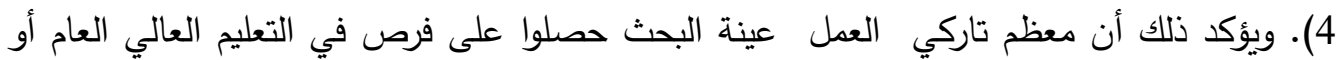

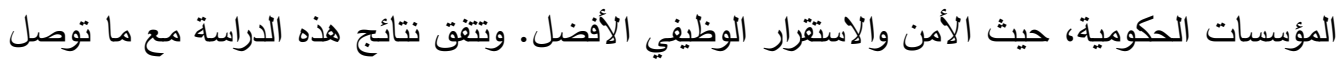
إليه (Al-Atrkjil. et al.2018) في دراسة بعنوان الأمن الوظيفي ودوره في انخفاض العمل في الجامعات الأهلية في أربيل. وكذلك مع دراسة( (Chowdhury,2016:9; (Ramasamy \& Bint)

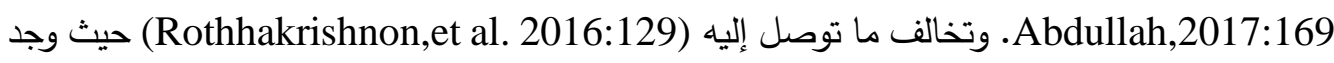
أن الأمن الوظيفي لا يثكل سبباً لدفع أعضاء هيئة التدريس إلى ترك العمل، وعلل ذلك بأنه قد يكون 
بسبب عدم وجود فرص عمل في ظل البطالة المرتفعة في بلد الدراسة - بنكلادش -. وتختلف أيضا مع دراسة (Al-Sarraf \& Helsa,2013:38) في عدد من الجامعات الأردنية الخاصة. 2- ضعف الاستقلالية في العمل: حيث بلغ المتوسط الحسابي (3.7170) وبانحراف معياري (1.40520) وبدلالة معنوية حيث قيمة (sig=.000) وهذه تعني أن عضو هيئة التدريس يتمتع باستقلالية ضعيفةK، وهذا يثبت صحة الفرضية الفرعية (1-6). وهذه النتيجة تتماشى مع دراسة Rothhakrishnon,et) al. 2016:129)

3- الافتقار إلى فرص التقدم الوظيفي: وتثمل فرص الترقية العلمية والزيادة في الراتب. فالمدرسون يتركون عملهم بسبب قلة أو ضعف فرص الترقية والزيادة في الراتب.وبلغ المتوسط الحسابي (3.6415) وبانحراف لتربه معياري قدره (19445) وهذا يثبت صحة الفرضية الفرعية (1-2). الأمر الذي يعني أحد أسباب دوران العمل لأعضاء هيئة التدريس في التعليم الجامعي الأهلي هو محدودية فرص التقدم الوظيفي. وتتقق نتائج

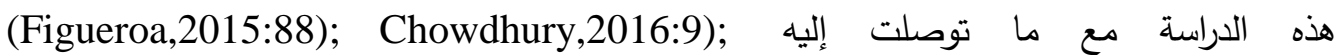
(Senggaravell,2018:264); (Josoh \& Yue,2019: 127). 4- جاء في المرتبة الرابعة كل من: أ- الافتقار إلى العدالة التتظيمية بمتوسط قدرة (3.5660) وبانحراف معياري (95090. حيث (Sig=.000). ) وهذا يثبت صحة الفرضية الفرعية (1-12). وهذه النتيجة تختلف ونتائج (Chowdhury,2016:9); (Thompson,2018:2); (Ramasamy \& Bint Abdullah,2017:169); (Albagami,2016:157 ) التنظيمية ليست سببا ذا أهمية في دوران العمل. ب- محدودية التسهيلات البحثية بمتوسط قدره (3.5660) وانحراف معياري (1.35177) بدلالة معنوية حيث (sig=.000) وهذا يثبت صحة الفرضية الفرعية (1-3). وهذه النتيجة تتفق مع دراسة أجريت

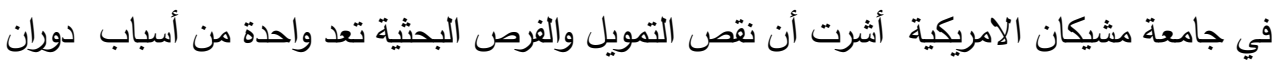
العمل (Joush \& Yue,2019:125) 5- وفي المرتبة الخامسة جاء كل من: أ- قلة الراتب:تعتبر الأجور أحد أبرز العوامل التي قد تدفع عضو هيئة التدريس إلى الانتقال من جامعة إلى أخرى. وفي هذه الدراسة بلغ المتوسط الحسابي (3.4528) وبانحراف معياري (1.38072) ودلالة معنوية قيمتها (sig=.000) الأمر الذي يشير إلى أن انخفاض الأجور يعد أحد أسباب دوران العمل، وهذا يثبت صحة الفرضية (1-1). وتتقق نتائج هذه الدراسة مع ما توصل التيل (Manogharan,2018:52); (Ramasamy \& Bint Abdullah,2017:1691) إليه (Chowdhury,2016:9); Josoh \& Yue,2019:127). ب- عبء العمل: المتمثل في زيادة عدد الساعات الدراسية والبحثية لعضو هيئة التدريس ولاسيما إن كانت من دون مقابل مادي، وهو ما معمول به في بعض الكليات الأهلية.حيث بلغ المتوسط الحسابي (3.4528) وبانحراف معياري و (1.23360) وبدلالة معنوية حيث قيمة (sig=.000). 
وهذا يثبت صحة الفرضية الفرعية (1-9). الأمر الذي يعد مؤشرا على أن زيادة عبء العمل أحد الأسباب الرئيسة لدوران العمل عينة البحث. وتتفق نتائج هذه الدراسة مع دراسة كل من Alssraf) \& Helsa, 2013: 38) (Manogharan, 2018: 52) (Ramasamy \& BintAbdullah, 2017: 169); (Senggaravellu, 2018: 249) 6- ضعف نظام الحوافز والمكافآت: حيث بلغ المتوسط الحسابي (3.4340) وبانحراف معياري (1.24822) وبدلالة معنوية حيث قيمة (sig=.000)، وهذا يثبت صحة الفرضية الفرعية (1-8). وتتفق نتائج هذه

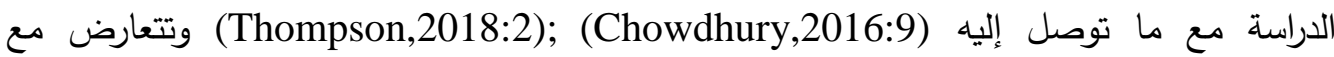

دراسة (Josoh \& Yue,2019:127).

7- موقع الكلية غير المناسب: الموقع الجغرافي قد يكون عامل طرد أو عامل جذب يؤثر على قرار عضو هيئة التدريس في البقاء أو المغادرة للكلية التي يعمل فيها، فقد بلغ المتوسط الحسابي (3.3962) وبانحراف معياري (1.40520) وبدلالة معنوية قيمتها (sig=000) وهذا يثبت صحة الفرضية الفرعية (1-5). الأمر الذي يعني أن موقع الكلية كان سببا وراء دوران عضو هيئة التدريس. وتتفق نتائج هذه

الدراسة مع ما توصل إليه (Chowdhury,2016:9); Senggaravellu 2018:264)) 8- قلة التقدير والاحترام في بيئة العمل: إن التقدير والاحترام يعد عاملاً أساسياً في استبقاء عضو هيئة التدريس أو تركه للعمل.وفي هذه الدراسة أُعتبر سببا وراء دوران العمل ،فقد بلغ الوسط الحسابي (3.3019) وبانحراف معياري (1.34072) وبدلالة معنوية (sig=000)، وهذا يثبت صحة الفرضية الفرعية (1- (1) 7) وتتفق نتائج هذه الدراسة مع ما توصل ليه(Chowdhury,2016:9); (Figueroa, 2015:88) وتتعارض مع دراسة (Senggaravellu 2018:248) 9- وجاء في المرتبة التاسعة الصراع المنظمي بمتوسط حسابي (3.2642) وبانحراف معياري (3.2642) وبدلالة معنوية حيث قيمة (sig=.000).وهذا يثبت صحة الفرضية الفرعية (1-10). وهذه النتيجة تختلف مع دراسة ( Chowdhury,2016:9) إذ وجد أنه لا تأثير للصراع على الدوران. في حين تتفق ودراسة ( Senggaravellu 2018:264); (Manogharan,2018:52)

$$
\text { 10- وجاء في المرتبة العاشرة كل من: }
$$

أ- سلوك رب العمل بمتوسط حسابي متساوِ قدره (3.1698) وبانحراف معياري (1.39692) وبدلالة معنوية حيث قيمة (sig=.000).وهذا يثبت صحة الفرضية الفرعية (1-11). وتتقق وهذه النتيجة ودراسة (Ramasamy \& Bint Abdullah, 2017: 169) وتتعارض دراسة

.(Chowdhury, 2016: 9)

ب- سمعة الكلية غير الجيدة بمتوسط حسابي قدره (3.1698) وبانحراف معياري و (1.34072) وبدلالة معنوية حيث قيمة (sig=.000). وبدلالة معنوية حيث قيمة (sig=.000). وهذا يثبت

صحة الفرضية الفرعية (1-13). 
مما تقدم يمكن القول بصحة الفرضية الأولى: التي تتص على أنه: (أسهمت جملة من العوامل الطاردة في

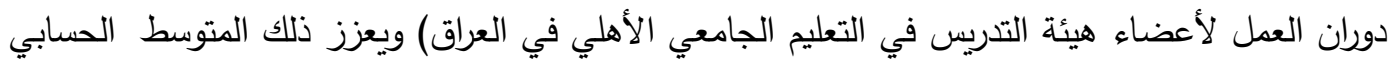
العام وقدره (3.4146) وبانحراف معياري (86049.) وبدلالة معنوية حيث قيمة (Sig=000). الفرضية الثانية: لا توجد فروق ذات دلالة إحصائية عند مستوى دلالة (0.05) للعوامل الطاردة تعزى إلى لمتغيرات الثخصية لأعضاء هيئة التدريس عينة البحث. لاختبار الفرضيات المتفرعة من هذه الفرضية (2-1، 2-2، 2-3) فقد تم استخدام اختبار Independent-sample t-test باعتبارها تمثل متغيرات (الجنس، المحالة الزوجية، والتحصيل

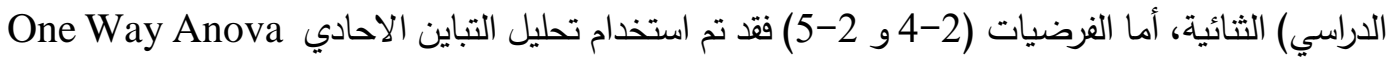
باعتبار متغيري (اللقب العلمي والعمر) وهي متغيرات تتكون من فئات متعددة وكانت النتائج كما مبين في وياي الجدول (4).

جدول (4): نتائج اختبار T واختبار One Way Anova

\begin{tabular}{|c|c|c|c|c|c|c|c|c|c|c|}
\hline \multicolumn{2}{|c|}{ العمر - العر } & \multicolumn{2}{|c|}{ اللقب العلمي } & \multicolumn{2}{|c|}{ التحصيل الدراسي } & \multicolumn{2}{|c|}{ الحالة الزوجية } & \multicolumn{2}{|c|}{ الجنس } & \multirow{3}{*}{ المتغير } \\
\hline Sig & $\mathrm{F}$ & Sig & $\mathrm{F}$ & Sig & $\mathrm{T}$ & Sig & $\mathrm{T}$ & Sig & $\mathrm{T}$ & \\
\hline .634 & .644 & .370 & 1.072 & .180 & .760 & .883 & .384 & 0.161 & 0.75 & \\
\hline
\end{tabular}

SPSS. المصدر: الجدول من إعداد الباحث بناء على نتائج التحليل الاحصائي لبرنامج

$$
\text { ومن الجدول (4) نلاحظ الآتي: }
$$

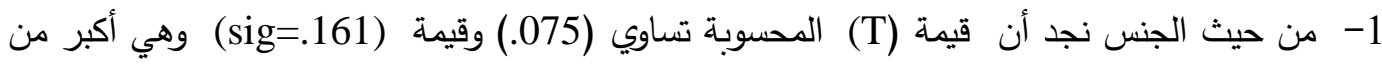
(05.) الأمر الذي يعني صحة الفرضية (2-1) التي تتص على أنه: ( لا توجد فروق ذات الدئ دلالة احصائية للعوامل الطاردة كمسبب لدوران العمل تعزى إلى متغير الجنس).

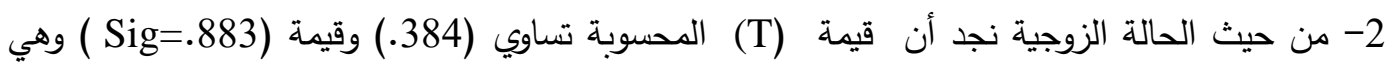

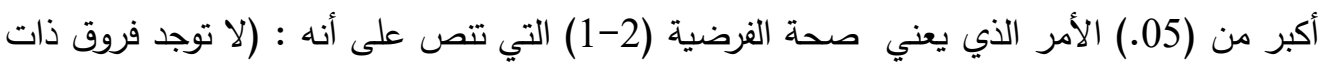
دلالة احصائية للعوامل الطاردة كمسبب لدوران العمل تعزى لمتغير الحالة الزوجية ).

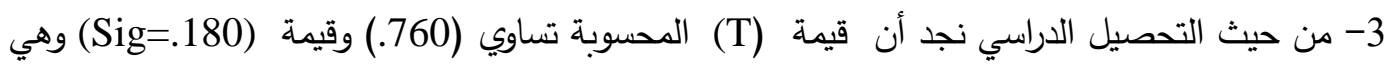
أكبر من (05.) الأمر الذي يعني صحة الفرضية (3-1) التي تتص على أنه : (لا توجد فروق ذات دلالة احصائية للعوامل الطاردة كمسبب لدوران العمل تعزى لمتغير التحصيل الدراسي). 4- أما من حيث اللقب العلمي نجد أن قيمة (F) المحسوبة تساوي (1.072) وقيمة (Sig=.370) وهي لوني أكبر من (05.) الأمر يعني الذي صحة الفرضية (2-1) التي تتص على أنه : (لا توجد فروق ذات دلالة احصائية للعوامل الطاردة كمسبب لدوران العمل تعزى إلى متغير اللقب العلمي). 
5- ومن حيث متغير العمر نجد أن قيمة (F) المحسوبة تساوي (644.) وقيمة (sig=634) وهي أكبر من (05.) الأمر الذي يعني صحة الفرضية (2-1) التي تتص على أنه : ( لا توجد فروق ذات دلالية احصائية للعوامل الطاردة كمسبب لدوران العمل تعزى لمتغير العمر . إن النتائج المذكورة آنفاً تختلف مع دراسة (Heymann, 2016:16) من حيث متغير الجنس، لفركئ حيث وجدت فروق للعوامل الطاردة كسبب لدوران العمل وفق متغير الجنس لصالح الاناث، وتلتقي مع دمع دماند نتائجها من حيث متغيري العمر ومستوى التعليم، حيث لا توجد فروق ذات دلالة إحصائية.

$$
\begin{aligned}
& \text { الاستنتاجات والمقترحات : } \\
& \text { أولا: الاستنتاجات: }
\end{aligned}
$$

نظرا لتجانس عينة البحث من حيث أنهم أعضاء في هيئات التدريس في التعليم الجامعي الأهلي

$$
\text { فقد كانت إجاباتهم متقاربة وتعطي نتائج متماثلة، ومن الاستتناجات: }
$$

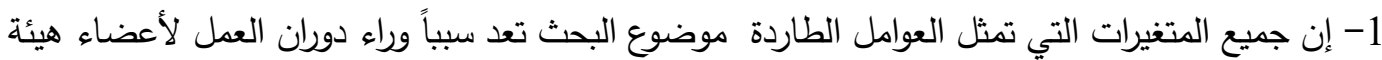

$$
\text { التدريس في التعليم الجامعي الأهلي وإن تفاوتت أهميها. }
$$

2- يعد الأمن والاستقرار الوظيقي أكثر العوامل المسببة لدوران العمل والسبب برأي الباحث هو هو عدم وجود

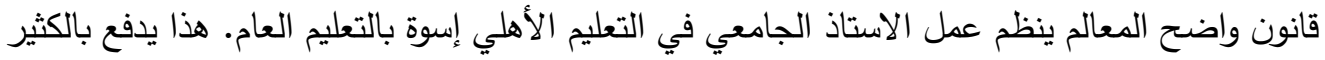
منهم بترك العمل حالما يحصل على فرصة عمل في القطاع الحكومي حتى وإن لم يكن قطاع التعليم. 3- لم تكن الأجور رغم أهميتها عاملا رئيساً وراء دوران العمل لأعضاء هيئة التدريس في التعليم الجامعي فئي

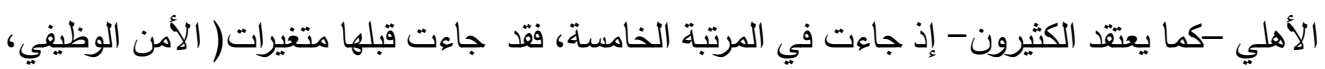
والاستقلالية في العمل، وفرص التقدم الوظيفي، والعدالة التنظيمية ومحدودية التسهيلات البحثية) وتليها ( زيادة عبء العمل، ونظام الحوافز، وموقع الكلية، وقلة التقدير والاحترام والصراع في بيئة العمل، ولئ

$$
\text { وسلوك رب العمل وسمعة الكلية). }
$$

4- نظرا لتجانس عينة البحث لم تكن هناك فروق ذات دلالة إحصائية للعوامل الطاردة كسبب وراء دوران العمل على أساس المتغيرات الديموغرافية ( الجنس، الحالة الزوجية ، التحصيل الدراسي واللقب العلمي). 5- مع أن نتائج التحليل الاحصائي أظهرت أن سلوك رب المعمل قد حلَّ في المراتب الأخيرة كسبب لدوران العمل إلا أنه من وجهة أخرى يعد أحد أهم الأسباب في ارتفاع أو انخفاض معدل دوران العمل باعتبار أن رب العمل قادر على اتخاذ التدابير اللازمة بما يمتلكه من سلطات للتقليل من أثر العوامل الطاردة والحد من مشكلة الدوران. فمن خلال اللقاء بعدد من عينة البحث يعزو البعض سبب تركهم العمل يعود

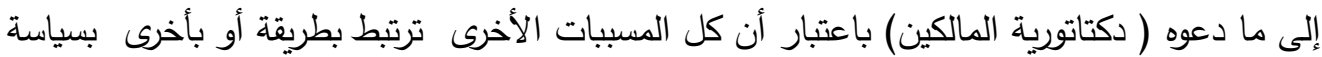


1- نظرا لكون أعضاء هيئات التدريس في التعليم الجامعي الأهلي المحور الأساسي في نجاح العملية التعليمة، وإن دورهم لا يقل أهمية عن أقرانهم في التعليم الجامعي العام. فإن على مؤسسات التعليم الجامعي الأهلي أن تعمل على إجراء تحسينات في الجوانب الوظيفية لجذب أعضاء هيئة التدريس والاحتفاظ بهم لأطول فترة ممكنة، وعلى كافة الأطراف صناع القرار وراسمي السياسات ممثلة بوزارة التعليم العالي وإدارة الجامعات والكليات الأهلية ومالكيها أن تعمل على وضع القعاه القوانين والأنظمة وتحديد

السياسات والممارسات التعليمية وتتفيذها للحد من دوران العمل في التعليم الجامعي الأهلي ومنها: 2- إعادة النظر بقانون التعليم الأهلي الجامعي الحالي بما يضمن حقوق عضو هيئة التدريس ومنها أن يتساوى في الحقوق والواجبات أسوة بأقرانهم في التعليم العام، من شأنه أن يحد من هجرة الكفاءات العلمية خارج مؤسسات التعليم الأهلي، وأن تتولى هيئة التعليم الأهلي متابعة تتفيذ هذه الآلية. 3- تمتين العلاقة بين الكليات الأهلية وأعضاء هيئة التدريس المبنية، وأن تبنى على الوئام والثقة المتبادلة التي من شأنها عدم إثارة ردود الفعل السلبية اتجاه السياسات الادارية والتتظيمية التي تتبناها الكلية. 4- تحسين بيئة العمل من حيث توفير الاليات اللازمة وإجراء الاصلاحات في الجوانب الوظيفية لجذب الجباه أعضاء هيئة التدريس والاحتفاظ بهم. وتقديم البرامج التدريبية المفيدة لتهيئة المعينين حديثا خاصة فئة

$$
\text { الثباب قليلي الخبرة. }
$$

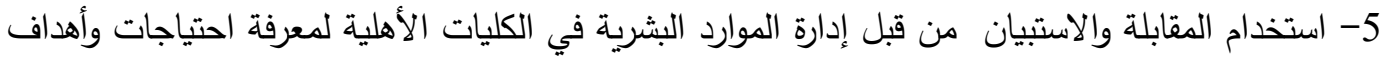
وآراء أعضاء هيئات التدريس عما يدور في الكلية كإجراءات استباقية تتخذها إدارة الكلية والعمل على الاستجابة لها.

$$
\begin{aligned}
& \text { 6- إجراء بحوث أخرى عن دوران العمل منها على سبيل المثال: } \\
& \text { أ- تأثير العوامل الجاذبة ( الخارجية ) على دوران العمل لأعضاء هيئة التدريس. } \\
& \text { ب- تكاليف دوران العمل لأعضاء هيئة التدريس في التعليم الجامعي الأهلي. }
\end{aligned}
$$

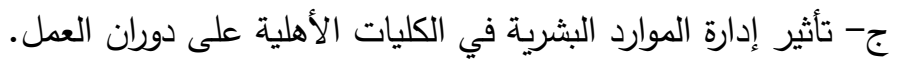

\section{References}

Al-Atarrakji, Osama Muhammad and Mahmoud, Yazan Nafi 'and Maarouf, Anas Maan Taher (2018). "Job security and its role to reducing labour turnover in educational organizations - a case study in private universities - Erbil-", Journal of Jehan University - Erbil Scientific Journal, Issue 2, Part B, pp. 283-3002.

Albaqami, Adi (2016), Determination of turnover intention among faculty member in Saudi public universities. A dissertation submitted in partial fulfillment of the requirement of business school for the degree of doctor of philosophy, university of Salford. 
Allen D.G., Reen W.R., Moffitt K.R. \& Karen R.M. (2007),"Risky business: The role of risk in voluntary turnover decision", Human Resource Management, Vol.17, p.p.305-318

Al-Sarraf, Zaki and Helsa, Aoun (2013), "Factors affecting on labour turnover for faculty members in private Jordanian universities," Al-Rafidain University College of Science Journal , No. 32, p. 25-44.

Andrea Bumann(2010). The impact of turnover and the benefit of stability in the nursing workforce, available on: www.human-resourceshealth.com/.../1478-4491-8

Choon Y. O., Kek C. G. Teng T. Y.\& Tan C. E. (2013),"Impact of demographic antecedent toward turnover intention among academic staff in Malaysian private universities" , Australian d Applied Sciences, Vol.6,No.6,p.p.46-54.

Chowdhury, Md. Sohel(2016), "A quantitative study on push,pull and personal factors affecting employees turnover intention: A case of national commercial banks(NCBs) in Bangladesh", Information and Knowledge Management, Vol. 6, No. 9, pp.1-14.

Griffeth J.M.; Hom P.W.; \&Gaertner S. (2000), "A meta-analysis of antecedent and correlate of employee turnover: update, moderator test and research implication for the next millennium", Journal of Management, Vol. 26, No.3, p.p. 463-488.

Hammond H.\&kutsanedzie(2015)," Lucture turnover and its affect on the performance of student: A case study of Accra polytechnic", Open Access Journal, available on: http://creativecommons.org/licenses/by/4.0/

Henry Ongor(2007, "Areview of literature on employee turnover", African journal of business management, Vol. 1,No.3, pp. 645-654.

Heymann, Marinus(2010), The impact of demographics on voluntary labor turnover in South Africa, A research project submitted to the Gordon Institute of business science, University of Pretoria in partial fulfillment of the requirement the for the degree of Master of business administration.

Holtom, Brook C. ; Mitchell, Trance R. \& Lee Tomas W.(2008), "turnover and retention research: A glance at the past, a closer review of the present and venture in the futer", Academy of Management Annals, Vol.2, No.1, p.p. 231-274

Iqtidar Ali shah; Zainab Faker; M. Shakil Ahmad \& kalid Zaman (2010), "Measuring push, pull and personal factor affecting turnover intention: A case of university teacher in Pakistan", Review of Economic Business Study, Vol.3, NO.1, pp. 167- 192.

Jusoh, D. R. \& Yue Wang (2019), "Job satisfaction and turnover intention influence of organization performance: Experience at higher education institution in Shanghai China", Journal of Education and Social Science, Vol.13, no.1, p.p.123-128.

Manogharan M. W.; Thivaharan T. \& AbdRahman R.(2018),"Academic staff retention in private higher education institute- Case study of private colleges

TANMIYAT AL-RAFIDAIN (P-ISSN: 1609-591X; E-ISSN: 2664-276X) تنمية الرافدين 
in Kuala Lampur", International Journal of Higher Education, Vol.7,No.3. p.p.52-78.

Martin,T.W.(1979)," Modeling the turnover process", Journal of management studies,Vol.17,No,3,pp261-174

Mobley,W.H.(1982),"Some answered question in turnover and research" The academy of management review,Vol.7,No,1,p.p.111-116

Muhmmad, Zohaib Sufyan (2016), "Roll of push vs pull factors in employee jib switch decision", Journal of Independent Study and Research, Vol.8, No. 1,pp.95-105.

Nair,Sudhashin; Mew,L.U. \& cheik,A. N.(2016), "Internal push factor and external pull factor and their relation wither lectures turnover", International Journal of Business and Management, Vol.11, No.2, p.p.110-126

Pack, Simon M. \& Won Doyean (2017),"from push to pull: Factor influencing turnover decision of middle- level athletic administration", Journal of physical Education and Sport, vol.17, no.1, pp,117-121.

Rothakrishnoe T., Imm,N.S.\&Kok T. K. (2016), "Turnover intention of lecturers in private universities in Malaysia", Social Science and Humanities, Vol. 24, pp.129-146.

Semmer,Narbet K.; Elfring, Achim; Baillod,Jurg \& Beehr, Terry A. (2014),"Push and pull motivation for Quitting: A three wave investigation of predictor and consequences of turnover", Organization Psychology, Vol.58,no.4,pp.173-185

Senggaravellu S. Nair (2018).Push and pull factor in relation to employee job satisfaction and turnover intention: A study of lectures in the business faculty of Malaysian private university, Doctor of philosophy, Faculty of Accounting and Management, University Tunku Abdul Rahman.

Simon.M.Pack \& doyeon Wan (2017), "From push to pull: Factor influencing turnover decision of middle-level athletic education and sport", Journal of physical education and sport, vol.17, No. 1,pp.117-121.

Siyanbola,T. Omowumi (2015), "the adoption of exit interview as employee turnover management tool in Nigeria SEMA and the geniuses in employee exit reason", The 2015 Wei international Academic Conference Proceeding, Harvard, USE, available on https://www.westeastinstitute.com

Thompson, Jonas (2018),Examine teacher turnover and its effect on academic performance of Mare Hil School complex, A partial fulfillment of the requirement for the award of master of business administration degree in general management to collage of humanities and legal studies, University of Copa coast, Accra.

Tracey JM Bruce \& Hinkin Timothy R, (2008), "Contextual factor and cost profiles associated with employee turnover", Cornell Hospitality quarterly, Vol.49, NO.1, pp.12-27.

Wang Yifeng; Li Zeyuan; Wang Yue \& Gao Fang (2017), "Psychological contract and turnover intention: The mediating role of organization commitment", Journal of Human Resource and Sustainability Study, Vol.5, p.p.21-35.

TANMIYAT AL-RAFIDAIN (P-ISSN: 1609-591X; E-ISSN: 2664-276X) تنمية الرافدين 